\title{
In vitro colonic metabolism of coffee and chlorogenic acid results in selective changes in human faecal microbiota growth
}

\author{
Charlotte E. Mills, Xenofon Tzounis, Maria-Jose Oruna-Concha, Don S. Mottram, Glenn R. Gibson \\ and Jeremy P. E. Spencer* \\ Department of Food and Nutritional Sciences, University of Reading, Whiteknights, Reading RG6 6AP, UK
}

(Submitted 6 June 2014 - Final revision received 7 October 2014 - Accepted 18 October 2014 - First published online 26 March 2015)

\begin{abstract}
Coffee is a relatively rich source of chlorogenic acids (CGA), which, as other polyphenols, have been postulated to exert preventive effects against CVD and type 2 diabetes. As a considerable proportion of ingested CGA reaches the large intestine, CGA may be capable of exerting beneficial effects in the large gut. Here, we utilise a stirred, anaerobic, pH-controlled, batch culture fermentation model of the distal region of the colon in order to investigate the impact of coffee and CGA on the growth of the human faecal microbiota. Incubation of coffee samples with the human faecal microbiota led to the rapid metabolism of CGA $(4 \mathrm{~h})$ and the production of dihydrocaffeic acid and dihydroferulic acid, while caffeine remained unmetabolised. The coffee with the highest levels of CGA $(P<0 \cdot 05$, relative to the other coffees) induced a significant increase in the growth of Bifidobacterium spp. relative to the control vessel at $10 \mathrm{~h}$ after exposure $(P<0 \cdot 05)$. Similarly, an equivalent quantity of CGA $(80.8 \mathrm{mg}$, matched with that in high-CGA coffee) induced a significant increase in the growth of Bifidobacterium spp. $(P<0 \cdot 05)$. CGA alone also induced a significant increase in the growth of the Clostridium coccoides-Eubacterium rectale group $(P<0 \cdot 05)$. This selective metabolism and subsequent amplification of specific bacterial populations could be beneficial to host health.
\end{abstract}

Key words: Coffee (Coffea spp.): Colonic microbiota: Chlorogenic acids

The effects of dietary polyphenols on human health has primarily focused on outcomes associated with $\mathrm{CVD}^{(1)}$, type 2 diabetes ${ }^{(2)}$ and neurodegenerative disorders ${ }^{(3)}$, through the impact of derived metabolites on various cell populations after absorption. Coffee is a good source of polyphenols, in particular chlorogenic acids (CGA), with one cup delivering between 15 and $325 \mathrm{mg}^{(4)}$, although coffee processing, in particular roasting, is known to dramatically reduce the levels of CGA in coffee ${ }^{(5)}$. However, CGA is poorly absorbed in the upper gastrointestinal tract, with studies conducted in ileostomy patients suggesting that only about one-third of ingested CGA is absorbed in the small intestine, with the remainder entering the large gut unmetabolised ${ }^{(6,7)}$. Further bacterial metabolism occurs here ${ }^{(8,9)}$, with most undergoing cleavage of the ester link between quinic acid and caffeic acid. Released caffeic acid may be absorbed intact or, more probably, further metabolised to O-methylated, sulphated and glucuronidated derivatives $^{(10,11)}$, as well as to dihydro metabolites such as dihydrocaffeic acid and dihydroferulic acid and their corresponding sulphates ${ }^{(11)}$.

The colonic microbiota are thought to play a central role in human health, with links emerging with respect to disorders such as irritable bowel syndrome ${ }^{(12)}$, travellers' diarrhoea ${ }^{(13)}$, autism $^{(14)}$ and obesity ${ }^{(15)}$.

As such, beneficial modulation of the gut bacteria may aid in the prevention of such diseases ${ }^{(16)}$.

Prebiotics resist digestion/absorption in the upper gastrointestinal tract, and selectively stimulate the growth and/or activity of intestinal bacteria associated with health ${ }^{(17)}$, leading to a healthier lower gut ${ }^{(18)}$.

Notably, many prebiotics increase the levels of bifidobacteria $^{(19,20)}$ that are known to prevent colonisation of pathogens by competitive exclusion, to enhance epithelial barrier integrity, regulate the immune system and have an anti-inflammatory response (reviewed in $\mathrm{Ng}$ et al. $^{(21)}$ ). However, other bacterial groups, such as Clostridium coccoides-Eubacterium rectale, may also act beneficially in the large intestine to prevent the development of obesity and other related diseases ${ }^{(22)}$, and have been shown to increase post-consumption of polyphenols, namely isoflavones ${ }^{(23)}$.

Previous data have highlighted the potential of polyphenolcontaining foods/beverages, such as fruit, cocoa and wine, to modulate the microbiota in a beneficial way ${ }^{(24-27)}$. As a high proportion of coffee CGA $(55-67 \%)^{(6,7)}$ reach the colon

Abbreviations: CGA, chlorogenic acid; CQA, caffeoylquinic acid; FOS, fructo-oligosaccharide; LC, liquid chromatography.

*Corresponding author: Professor J. P. E. Spencer, fax + 44118378 7708; email j.p.e.spencer@reading.ac.uk 
unmetabolised, there is a potential for them to exert prebioticlike actions. In the present study, we exploit in vitro methods to investigate the colonic metabolism of coffee CGA and the subsequent effect of such metabolism on the growth of the human colonic microbiota.

\section{Materials and methods \\ Chemicals and reagents}

5-Caffeoylquinic acid (5-CQA), caffeine, zinc acetate, potassium ferrocyanide trihydrate, glacial acetic acid, sucrose, SDS, paraformaldehyde and lysosyme were obtained from Sigma-Aldrich. Ethanol, HPLC grade; methanol, acetonitrile and hydrochloric acid, liquid chromatography-MS (LC-MS) grade; formic acid, acetonitrile, methanol and water were obtained from Fisher Scientific. Peptone water, yeast extract, $\mathrm{NaCl}$, dipotassium phosphate, monopotassium phosphate, sodium bicarbonate, magnesium sulphate heptahydrate, calcium chloride hexahydrate, Tween-80, haemin, phylloquinone (vitamin $\mathrm{K}_{1}$ ), L-cystine, bile salts, resazurin, PBS tablets were obtained from Oxoid Limited. ProLong ${ }^{\circledR}$ Gold antifade reagent was obtained from Invitrogen. Raftilose P95 FOS (a positive prebiotic control) was purchased from Orafti. Oligonucleotide probes (EUB338/ II/III, CHIS150, LAB158, BAC303, EREC482 and BIF164) were commercially synthesised and labelled with Cy3 by MWG Biotech Limited. Aquasonic ${ }^{\circledR} 100$ ultrasound gel was purchased from Parker Laboratories Inc. Deionised water was obtained using a Purite dispenser.

\section{Coffee samples}

Coffee was sourced commercially. Nescafé Green Blend, Nescafé Gold Blend and Nescafé Original were weighed in $1.2 \mathrm{~g}$ portions to represent an estimated equivalent of one cup of coffee, delivering $80.8,33.9$ and $33.8 \mathrm{mg}$ CGA, respectively, as reported previously ${ }^{(28)}$. All coffee samples had a similar content of energy $(4 \mathrm{~kJ})$, protein $(0 \cdot 1 \mathrm{~g})$, carbohydrate $(0 \cdot 1 \mathrm{~g})$, fat $(0 \mathrm{~g})$ and fibre $(0 \cdot 1 \mathrm{~g})$, although Nescafé Green Blend contained $0.05 \mathrm{~g}$ fibre per cup. All the three coffee samples contained similar levels of caffeine (53 (sEM 0.4) mg).

\section{Batch culture}

Faecal samples were collected from three healthy individuals who had no known pre-existing gastrointestinal conditions, but all of whom were regular coffee consumers on experimental days and were processed immediately. Individuals who had ingested antibiotics or any other medicines known to affect the gastrointestinal tract, those who were regular consumers of pre- or probiotics, or who had taken part in a similar study at the University of Reading within the last 6 months were excluded from the study. Fibre or coffee intake was not restricted before donating faecal samples. Faecal samples were diluted at 1:10 (w/v) with anaerobic phosphate buffer $(0 \cdot 1 \mathrm{M} ; \mathrm{pH} 7 \cdot 4)$ and homogenised using a stomacher (Seward Stomacher ${ }^{\circledR} 80$ Biomaster) for $2 \mathrm{~min}$, and this faecal slurry was used to inoculate batch culture vessels. Batch culture vessels were prepared to mimic physico-chemical conditions in the distal region of the human colon. These culture vessels with a volume of $300 \mathrm{ml}$ were sterilised and $135 \mathrm{ml}$ of sterile basal nutrient medium (peptone water $(2 \mathrm{~g} / \mathrm{l})$, yeast extract ( $2 \mathrm{~g} / \mathrm{l}), \mathrm{NaCl}(0 \cdot 1 \mathrm{~g} / \mathrm{l})$, dipotassium phosphate (0.04 g/l), monopotassium phosphate $(0.04 \mathrm{~g} / 1)$, sodium bicarbonate $(2 \mathrm{~g} / \mathrm{l})$, magnesium sulphate heptahydrate $(0 \cdot 01 \mathrm{~g} / \mathrm{l})$, calcium chloride hexahydrate $(0 \cdot 01 \mathrm{~g} / \mathrm{l})$, Tween-80 $(2 \mathrm{ml} / \mathrm{l})$, haemin $(50 \mathrm{mg} / \mathrm{l})$, phylloquinone (vitamin $\mathrm{K}_{1}, 10 \mathrm{ml} / \mathrm{l}$ ), L-cysteine $(0.5 \mathrm{~g} / \mathrm{l})$, bile salts $(0.5 \mathrm{~g} / \mathrm{l})$, resazurin $(1 \mathrm{mg} / \mathrm{l})$ and distilled water) were added to each vessel. The medium was set up with a flow of $\mathrm{O}_{2}$-free $\mathrm{N}_{2}$ gas $(15 \mathrm{ml} / \mathrm{min})$ for a minimum of $12 \mathrm{~h}$ in order to achieve an anaerobic environment. Before inoculation with the faecal material and coffee, the basal medium was maintained at $37^{\circ} \mathrm{C}$ and the $\mathrm{pH}$ was adjusted to $\mathrm{pH} 6.8$ and was maintained between $\mathrm{pH} 6.7$ and 6.9 using an Electrolab $\mathrm{pH}$ controller with feeds of $0.5 \mathrm{M}-\mathrm{HCl}$ and $0.5 \mathrm{M}-\mathrm{NaOH}$, as appropriate. The coffee samples were added and the $\mathrm{pH}$ was allowed to adjust to the acceptable range. Finally, $15 \mathrm{ml}$ of the faecal slurry were added to each of the vessels and allowed to run under the conditions as described for $24 \mathrm{~h}$. During this period, $3 \mathrm{ml}$ samples were taken from each of the vessels at 0, 4, 10 and $24 \mathrm{~h}$ for fluorescent in situ hybridisation analysis to assess quantitative changes in the gut microbiota, and for LC-MS and HPLC analysis to assess the metabolism of coffee polyphenols.

\section{Bacterial enumeration}

Samples taken from the batch culture vessels were added to cold $4 \%(\mathrm{v} / \mathrm{v})$ paraformaldehyde and stored for $4 \mathrm{~h}$ at $4{ }^{\circ} \mathrm{C}$ to fix the bacteria. Following this, fixed samples were centrifuged at $1500 \mathrm{~g}$ for $15 \mathrm{~min}$ and washed twice with PBS (0.1 M; pH 7). Afterwards, the remaining pellets were resuspended in a PBS (99\%)-ethanol mixture $(1: 1, \mathrm{v} / \mathrm{v})$ and stored at $-20^{\circ} \mathrm{C}$ for at least $1 \mathrm{~h}$ before fluorescent in situ hybridisation analysis. For hybridisation, samples were vortexed for $5 \mathrm{~s}$ and diluted, as appropriate, in a PBS-SDS solution (10\%, 1:1, v/v). The samples were vortexed and $20 \mu \mathrm{l}$ were added to a well on a six-well plate (Tekadon, Inc.). Plates were dried using a desktop plate incubator (Grant Boekel ISO20) for $15 \mathrm{~min}$ at $48^{\circ} \mathrm{C}$. Samples prepared for LAB158 were further treated to make bacterial cells more permeable to the probe. A $20 \mu$ lysosyme solution $(1 \mathrm{mg} / \mathrm{ml}$ sterile water) was applied to these wells, which were further incubated at $37^{\circ} \mathrm{C}$ for $15 \mathrm{~min}$. Slides were exposed to 50, 80 and $96 \%(\mathrm{v} / \mathrm{v})$ ethanol for 3 min each and dried using a desktop incubator. Oligonucleotide probes ( $50 \mathrm{ng} / \mu \mathrm{l})$, labelled with the fluorescent dye Cy3, were used to identify specific bacteria; they work by differentiating bacteria by targeting specific $16 \mathrm{~S}$ rRNA sequences. The probes used for enumerating specific bacteria were as follows: BIF164 (for Bifidobacterium spp.) (29); BAC303 (for Bacteroides spp.) ${ }^{(30)}$; LAB158 (for Lactobacillus/Enterococcus spp.) ${ }^{(31)}$; EREC482 (for the C. coccoides-E. rectale group) ${ }^{(32)}$; CHIS150 (for the C. histolyticum group); EUB338/II/III (for total bacteria $)^{(33)}$. A $50 \mu \mathrm{l}$ probe solution $(5 \mu \mathrm{l}$ of probe in $50 \mu \mathrm{l}$ of hybridisation buffer $(5 \mathrm{~m}-\mathrm{NaCl}, 1 \mathrm{~m}$-Tris- $\mathrm{HCl}$, deionised water, $10 \%(\mathrm{w} / \mathrm{v})$ SDS and formamide prepared according to 
the probe)) was added to each well. The wells were stored in an airtight container at the appropriate temperature ( 46 or $50^{\circ} \mathrm{C}$ ) for $4 \mathrm{~h}$. The slides were then washed with warm buffer ( $5 \mathrm{M}-\mathrm{NaCl}, 1 \mathrm{~m}$-Tris- $\mathrm{HCl}(\mathrm{pH}$ 8) and $0.5 \mathrm{~m}$-EDTA $(\mathrm{pH} 8)$ ) for $15 \mathrm{~min}$ and then immediately plunged into cold water. The slides were dried using compressed air before $5 \mu \mathrm{l}$ of antifade and a cover slip was applied. All slides were stored for at least $8 \mathrm{~h}$ in the dark at $4^{\circ} \mathrm{C}$ before microscopic examination. For each well, bacterial counts were obtained in fifteen different fields of view using a Nikon Eclipse E400 microscope.

\section{Liquid Chromatography-MSn}

The coffee samples and the inoculated batch culture media were analysed by LC-MS ${ }^{n}$ using electrospray ionisation to identify principal CGA and key CGA metabolites (in the media). LC-MS analyses were performed using an Agilent 1200 Series LC system (Agilent) equipped with a binary pump, a degasser, an auto-sampler, a thermostat, a column heater, a photodiode array detector and an Agilent 1100 Series LC/MSD mass trap spectrometer. Separation of samples was achieved using a Zorbax SB C18 column $(2 \cdot 1 \times 100 \mathrm{~mm}, 1 \cdot 8 \mu \mathrm{m}$; Agilent $)$, and LC conditions were as follows: injection volume, $10 \mu \mathrm{l}$; column temperature, $25^{\circ} \mathrm{C}$; binary mobile system, (A) $0 \cdot 1 \%$ $(\mathrm{w} / \mathrm{v})$ of aqueous formic acid and (B) $0 \cdot 1 \%(\mathrm{w} / \mathrm{v})$ of formic acid in acetonitrile; flow rate, $0.2 \mathrm{ml} / \mathrm{min}$. A series of linear gradients was used for separation ( $\mathrm{min} / \% \mathrm{~B})$ : 0/0, 5/4, 40/25, $55 / 50$ and $60 / 50$. MS was performed in the negative-ion mode (scan range, $m / z \quad 100-800 \mathrm{Da}$; source temperature, $350^{\circ} \mathrm{C}$ ). All solvents used were of LC-MS grade. The eluent was monitored by a photodiode array detector at 254, 280, 320,370 and $520 \mathrm{~nm}$, and spectra of products were obtained over the $220-600 \mathrm{~nm}$ range. All data were analysed using Bruker Daltonics Data Analysis 3.3.
HPLC

The coffee samples and the inoculated batch culture media were analysed by HPLC to quantify CGA, using an Agilent 1100 Series LC fitted with a $\mathrm{C}_{18}$ Nova Pak ${ }^{\circledR}$ column $(250 \times 4.6 \mathrm{~mm}$ inner diameter and $5 \mu \mathrm{m}$ particle size) and a $\mathrm{C}_{18}$ Nova Pak ${ }^{\circledR}$ guard column (Waters Limited). The mobile phases consisted of $5 \mathrm{M}-\mathrm{HCl}(0 \cdot 1 \%)$ in $95 \%$ water (phase A) and $5 \%$ methanol, and $5 \mathrm{M}-\mathrm{HCl}(0 \cdot 1 \%)$ in $50 \%$ acetonitrile and $50 \%$ water (phase B) pumped through the column at $0.7 \mathrm{ml} / \mathrm{min}$. An aliquot $(50 \mu \mathrm{l})$ of the sample was injected and separated using a gradient system (min/\%B): 0/5, 5/5, 40/50, 55/100, 59.9/100 and 60/5. The eluent was monitored by a photodiode array detector at $254,280,320,370$ and $520 \mathrm{~nm}$, and spectra of the products were obtained over the $220-600 \mathrm{~nm}$ range. Quantification of CGA was obtained at $320 \mathrm{~nm}$. A standard curve was produced using 5-CQA (00.1-0.6 mm), and a linear relationship was obtained with a correlation coefficient of $>0.98$. Quantity was expressed as 5-CQA and presented as an equivalent quantity as that found in the human colon after ingestion of one cup of coffee (assuming that two-thirds of CGA reach the colon). All data were analysed using Agilent Chem Station software.

\section{Statistical analysis}

A paired Student's $t$ test was used to test for significant differences $(P<0.05)$ in bacterial enumeration between the 0 and $10 \mathrm{~h}$ time points, using XLSTAT statistical analysis add-in for Microsoft Excel 2010.

\section{Results}

Metabolism of chlorogenic acids by human faecal bacteria In agreement with previous investigations ${ }^{(28)}$, eight CGA were identified in the faecal batch culture vessels inoculated with

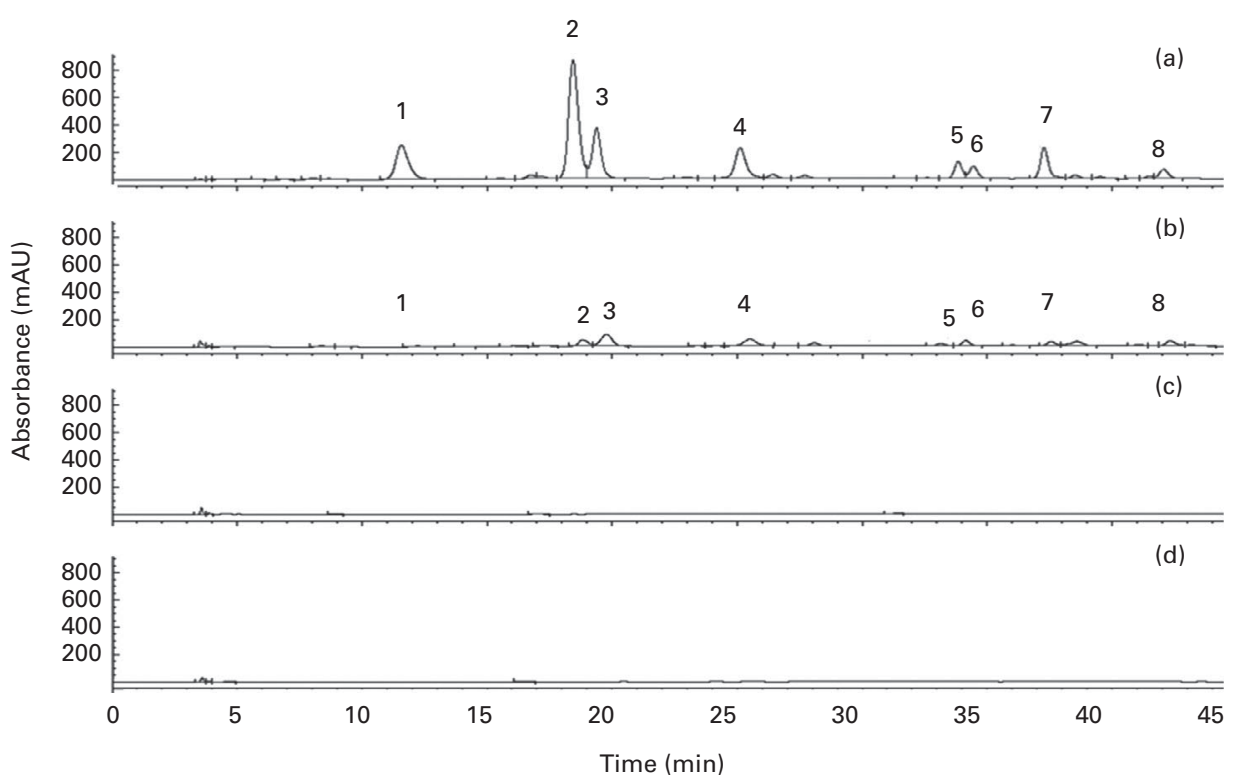

Fig. 1. HPLC chromatograms at $320 \mathrm{~nm}$ of Nescafé Green Blend vessel samples demonstrating the depletion of chlorogenic acids over time: (a) $0 \mathrm{~h}$, (b) $4 \mathrm{~h}$, (c) $10 \mathrm{~h}$ and (d) $24 \mathrm{~h}$. mAU, milli absorbance units; 1, 3-caffeoylquinic acid (3-CQA); 2, 5-CQA; 3, 4-CQA; 4, 5-feruloylquinic acid (5-FQA); 5, 4-FQA; 6, 3,4-diCQA; 7, 3,5-diFQA; 8, 4,5-FQA. 
Table 1. Negative-ion $\mathrm{MS}^{2}$ fragmentation data for identification of chlorogenic acids in coffee at $\mathrm{Oh}$

\begin{tabular}{|c|c|c|c|c|c|c|}
\hline \multirow{3}{*}{$\begin{array}{l}\text { Compounds } \\
\text { 3-CQA }\end{array}$} & \multirow{3}{*}{$\frac{\text { Retention time }}{15 \cdot 3}$} & \multirow{3}{*}{$\begin{array}{c}\frac{\mathrm{MS}^{1}}{\text { Parent ion }} \\
353.0\end{array}$} & \multicolumn{4}{|c|}{$\mathrm{MS}^{2}$} \\
\hline & & & \multirow{2}{*}{$\begin{array}{c}\text { Base peak }(\mathrm{m} / \mathrm{z}) \\
190 \cdot 7\end{array}$} & \multicolumn{3}{|c|}{ Secondary peaks $(\mathrm{m} / \mathrm{z})$} \\
\hline & & & & 178.9 & 134.8 & \\
\hline 4-CQA & $23 \cdot 1$ & $353 \cdot 0$ & $172 \cdot 7$ & $178 \cdot 7$ & $190 \cdot 7$ & $134 \cdot 8$ \\
\hline 5-CQA & $21 \cdot 9$ & $352 \cdot 8$ & $190 \cdot 7$ & & & \\
\hline 4-FQA & $32 \cdot 1$ & $367 \cdot 1$ & $178 \cdot 9$ & $190 \cdot 7$ & & \\
\hline 5-FQA & $30 \cdot 0$ & $367 \cdot 2$ & $190 \cdot 7$ & $172 \cdot 8$ & & \\
\hline 3,4-diCQA & 38.9 & $515 \cdot 0$ & 352.9 & $172 \cdot 7$ & & \\
\hline 3,5-diCQA & $40 \cdot 2$ & $515 \cdot 0$ & 352.9 & & & \\
\hline 4,5-diCQA & $42 \cdot 3$ & $515 \cdot 0$ & 352.9 & & & \\
\hline
\end{tabular}

CQA, caffeoylquinic acid; FQA, feruloylquinic acid.

coffee (Fig. 1). At $0 \mathrm{~h}$, these were as follows: 5, 4 and 3 isomers of CQA; 4 and 5 isomers of feruloylquinic acid; 3,4, 3,5 and 4,5 isomers of dicaffeoylquinic acid (diCQA; Fig. 1). Retention times and fragmentation patterns for the identification of CGA by $\mathrm{LC}-\mathrm{MS}^{n}$ are presented in Table 1 . No CGA was detected in the control vessel (without coffee inoculation). All CGA underwent metabolism over the $24 \mathrm{~h}$ period of incubation with the faecal microbiota (Fig. 1; Table 2), with the majority of CGA being metabolised by $10 \mathrm{~h}$ of incubation. Parallel to the loss of CGA, a number of new peaks appeared over the $24 \mathrm{~h}$ period (peaks 2, 3 and 4; Fig. 2), which were identified as dihydrocaffeic acid ([M $-\mathrm{H}]^{-} m / z \mathrm{MS}^{1}$ : 180.9, $\mathrm{MS}^{2}$ : 136.8) (peak 2), dihydroferulic acid $\left([\mathrm{M}-\mathrm{H}]^{-} \mathrm{m} / z \mathrm{MS}^{1}\right.$ : 194.8, $\mathrm{MS}^{2}$ : 135.8) (peak 4) and an unknown compound $\left([\mathrm{M}-\mathrm{H}]^{-} \quad m / z \quad \mathrm{MS}^{1}: \quad 377 \cdot 0, \mathrm{MS}^{2}: 202 \cdot 2,172 \cdot 8\right)$ (peak 3). Caffeine levels were similar in all the three coffee samples (53 (sEm 0.4) $\mathrm{mg}$ ) and remained unmetabolised throughout the experiment (Fig. 2), suggesting the selective metabolism of CGA by the microbiota. Pure CGA (5-CQA isomer, $80 \cdot 8 \mathrm{mg}$ ) was also rapidly metabolised to dihydrocaffeic acid $\left([\mathrm{M}-\mathrm{H}]^{-} m / z 180 \cdot 9,136 \cdot 8\right)$ and the unknown compound $\left([\mathrm{M}-\mathrm{H}]^{-} \mathrm{m} / z \mathrm{MS}^{1}: 377 \cdot 0, \mathrm{MS}^{2}: 202 \cdot 2,172 \cdot 8\right)$ being identified after incubation with the microbiota; however, dihydroferulic acid was not observed.

\section{Chlorogenic acids induce changes in bacterial groups}

All coffee samples induced an increase in the growth of total bacteria (Fig. 3), at a similar magnitude to that observed with fructo-oligosaccharide (FOS), an established prebiotic, although this was only significant for Nescafé Green Blend and Nescafé Gold Blend $(P<0 \cdot 05)$, relative to the control vessel. Nescafé Green Blend was the only coffee that induced a significant increase in the growth of Bifidobacterium spp., with a similar magnitude to that observed with FOS (Fig. 3). All coffee samples failed to alter the growth of Lactobacillus/Enterococcus spp. (unlike FOS) or the C. histolyticum group (unlike FOS that induced a decrease) (Fig. 3). However, two of the three coffee samples (Nescafé Gold Blend and Nescafé Original) significantly increased the growth of the $C$. coccoides $-E$. rectale group relative to the control vessel, although FOS decreased the growth of this bacterial group. Finally, Bacteroides spp. increased to a similar magnitude in all the three coffee treatments, whereas a decrease in the growth of these bacteria was observed in response to FOS, albeit not significant (Fig. 3). Similar to that observed with the coffee treatments, pure CGA (5-CQA) increased the growth of Bifidobacterium spp. $(P<0.05)$ and the $C$. coccoides $-E$. rectale group $(P<0.05)$ (Fig. 4$)$, but there were no significant changes in the growth of total bacteria, Lactobacillus/Enterococcus spp., Bacteroides spp. or the C. histolyticum group, although it did induce a substantial decrease in the growth of the latter (Fig. 4). No significant changes were observed between the coffee treatments for any of the bacteria assessed.

\section{Discussion}

Prebiotics in the form of indigestible polysaccharides, predominantly inulin-type fructans ${ }^{(34)}$ and galacto-oligosaccharides ${ }^{(35)}$, have been widely studied for their ability to positively modulate the profile of the human colonic microbiota. However,

Table 2. Chlorogenic acids (CGA) in Nescafé Green Blend, Nescafé Gold Blend and Nescafé Original at $0,4,10$ and $24 \mathrm{~h}$

(Mean values with their standard errors)

\begin{tabular}{|c|c|c|c|c|c|c|c|c|c|}
\hline \multirow[b]{2}{*}{ Time (h) } & \multicolumn{3}{|c|}{ Nescafé Green Blend } & \multicolumn{3}{|c|}{ Nescafé Gold Blend } & \multicolumn{3}{|c|}{ Nescafé Original } \\
\hline & Mean* & SEM & $\% \dagger$ & Mean & SEM & $\%$ & Mean & SEM & $\%$ \\
\hline 0 & 75.44 & 8.13 & $100 \cdot 00$ & 25.00 & 2.04 & 100.00 & $27 \cdot 18$ & $4 \cdot 38$ & $100 \cdot 00$ \\
\hline 4 & 5.00 & 3.99 & 6.63 & 2.49 & 1.54 & 9.95 & 4.07 & 3.40 & 14.99 \\
\hline 10 & 1.87 & 1.68 & 2.47 & 0.37 & 0.22 & 1.49 & 0.56 & 0.34 & 2.05 \\
\hline 24 & 0.00 & 0.00 & 0.00 & 0.00 & 0.00 & 0.00 & 0.00 & 0.00 & 0.00 \\
\hline
\end{tabular}

${ }^{*} \mathrm{mg} \mathrm{CGA}$ in the vessel $(150 \mathrm{ml})$.

$\dagger \%$ of CGA remaining in the vessel in comparison with that at $0 \mathrm{~h}$. 



Fig. 2. (a-d) HPLC chromatograms at $280 \mathrm{~nm}(0,4,10$ and $24 \mathrm{~h}$, respectively) and (e-h) UV spectra of Nescafé Green Blend vessel samples demonstrating the formation of chlorogenic acid metabolites and the continued presence of caffeine. mAU, milli absorbance units. 1, Caffeine; 2, dihydrocaffeic acid; 3, unknown compound; 4, dihydroferulic acid.

there are various other food components that reach the colon largely unmetabolised from the upper gastrointestinal tract, including polyphenols, which are known to undergo only limited absorption in the small intestine ${ }^{(24-26)}$. A regular coffee consumer may consume up to $1 \mathrm{~g}$ CGA/d, with approximately $51-67 \%$ of these being estimated to reach the colon ${ }^{(6,7)}$. As such, coffee-derived CGA may represent a potential candidate for inducing a 'non-polysaccharide'-based prebiotic effect. In support of this, we show that coffee, equivalent to an oral dose of one cup ( $1.2 \mathrm{~g}$ instant powder), increases the growth of total bacteria to a similar magnitude to that observed with FOS. These changes were accompanied by the rapid and complete (by $24 \mathrm{~h}$ ) metabolism of CGA and 5-CQA. Notably, exposure of coffee to the microbiota led to the detection of two metabolites, dihydrocaffeic acid and dihydroferulic acid ${ }^{(11)}$, along with another unidentified metabolite. These metabolites were also detected following exposure to pure 5-CQA, although dihydroferulic acid was not produced in high amounts, perhaps because it is entirely or partially derived from an alternative CGA or a different CQA isomer.

All coffee samples increased the growth of Bifidobacterium spp., although the Nescafé Green blend coffee, which contained the highest amounts of CGA, was the only one to induce this growth significantly $(P<0.05)$. In support of CGA being the mediating compounds for these effects, an equivalent amount of 5-CQA (the most abundant CGA in coffee) also induced a significant increase in the growth of Bifidobacterium spp. Such increases in growth are biologically relevant as Bifidobacterium spp. have long been associated with positive health outcomes in the gut, through an enhancement of saccharolytic metabolism ${ }^{(36)}$, the production of organic fatty acids such as acetate and lactate, and their inherent anti-pathogenic capabilities ${ }^{(37)}$. Furthermore, some species of Bifidobacterium have been noted for their ability to inhibit the proliferation of colon cancer cells $^{(38)}$, particularly in elderly individuals ${ }^{(39,40)}$. Our data are in agreement with similar experiments using anthocyanins ${ }^{(41)}$ 


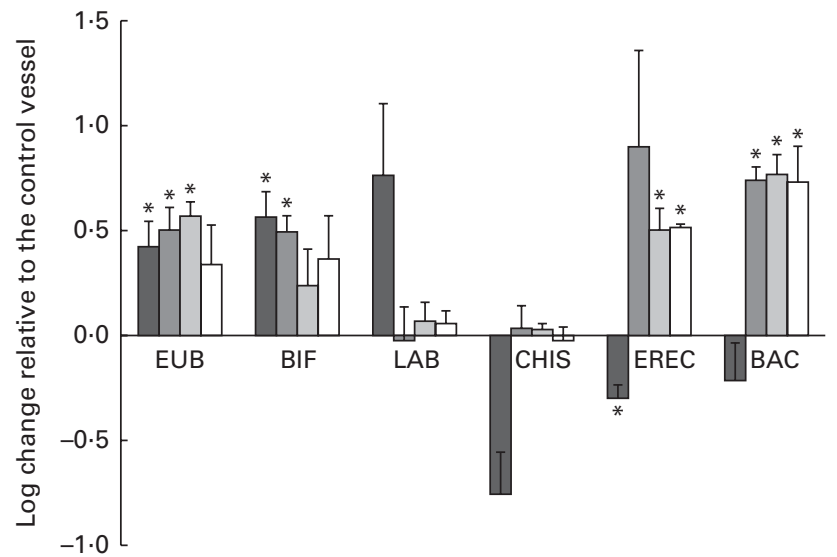

Fig. 3. Influence on colonic bacterial populations during the fermentation of FOS $(\square)$, Nescafé Green Blend ( $\square$ ), Nescafé Gold Blend ( $\square$ ) and Nescafé Original $(\square)$. Bacterial changes expressed as $\log _{10}$ cells $/ \mathrm{ml}$ relative to the control vessel. Values are means, with their standard errors represented by vertical bars $(n 3)$. ${ }^{*}$ Mean value was significantly different from that of the control vessel $(P<0.05)$. EUB, total bacteria; BIF, Bifidobacterium spp.; LAB, Lactobacillus/Enterococcus spp.; CHIS, Clostridium histolyticum group; EREC, C. coccoides-Eubacterium rectale group; BAC, Bacteroides spp.

and $(+)$-catechin ${ }^{(24)}$, and with human intervention studies using flavanol-rich cocoa $^{(25)}$ and coffee ${ }^{(42)}$ interventions. In support of our findings with respect to bacterial levels, the rapid metabolism of CGA upon exposure to the microbiota suggests that specific bacterial groups are capable of metabolising CGA. Indeed, Bifidobacterium spp. have previously been reported to exert esterase activity and, thus, would be capable of cleaving the caffeic acid moiety from its quinic acid counterpart ${ }^{(43)}$.

In contrast, neither the coffee treatments nor 5-CQA affected the growth of Lactobacillus/Enterococcus spp., highlighting the difference between them and classical polysaccharide prebiotics. Previous investigations with polyphenols suggest that increases in the growth of Lactobacillus/Enterococcus spp. are possible with anthocyanins ${ }^{(41)}$ and high-flavanol $\operatorname{cocoa}^{(44)}$, although our data are consistent with previous coffee data ${ }^{(42)}$. Furthermore, in contrast to the changes in bacterial growth after exposure to FOS, all the three coffee treatments induced an increase in the growth of the $C$. coccoides $-E$. rectale group. Although these increases in growth proved to be not significant after exposure to Nescafé Green Blend due to a large variation, numbers of this bacterial group increased by approximately $0.4 \mathrm{log}$, greater than that observed with the other coffee treatments containing lower amounts of CGA. In support of this change, pure 5-CQA induced a significant increase in the growth of this bacterial group $(P<0 \cdot 05)$, relative to the control vessel. E. rectale are known to possess butyrogenic potential. Butyrate is considered to have anti-inflammatory effects, as well as an ability to modulate the immune system and protect against oxidative stress $^{(45)}$, and unlike other clostridia (C. coccoides (XIA cluster) analysed here, it also possess the ability to ferment polysaccharides and disaccharides ${ }^{(46)}$ and, therefore, may well have the ability to metabolise CGA. The C. coccoides$E$. rectale group, as a whole, has been observed to be reduced in patients with ulcerative colitis, and increasing the colonisation is considered to be beneficial to this bacterial group specifically ${ }^{(47)}$. An increase in the growth of this bacterial group has previously been observed in response to (+)-catechin and (-)-epicatechin ${ }^{(24)}$ and in vivo after an intervention with cocoa flavanols ${ }^{(25)}$.

The increase in the growth of Bacteroides spp. observed after exposure of the microbiota to coffee may be relevant to human health as this genus is known to be capable of fermenting polysaccharides to yield organic acids ${ }^{(48)}$. As all the three coffee treatments increased the growth of this bacterial group to a similar magnitude, the changes may result due to other components than CGA, as 5-CQA had no significant influence on the growth of this bacterial group, in a similar manner to that observed with FOS. Similar observations were observed with respect to the growth of C. histolyticum, a bacterial group considered to be pathogenic, which did not alter in response to coffee treatment, but significantly decreased following exposure to 5-CQA. Previous data suggest that polyphenols consistently induce a decrease in the growth of the C. histolyticum group, for example malvadin-3-glucoside, enocianin (and gallic acid) ${ }^{(41)}$ as well as the flavanols (-)-epicatechin and (+)-catechin ${ }^{(24)}$, although in vivo flavanols have been shown to induce the growth of this bacterial group ${ }^{(25)}$.

In summary, our data suggest that coffee intake may be beneficial to the host via the potential of CGA (and potentially other coffee components) to selectively modulate the colonic microbiota. However, we accept that this is a preliminary investigation that is limited by a small donor number and although a robust model for the distal region of the colon, limitations of such investigations still prevail. A full colonic model, including pre-digestion of the coffee, would increase

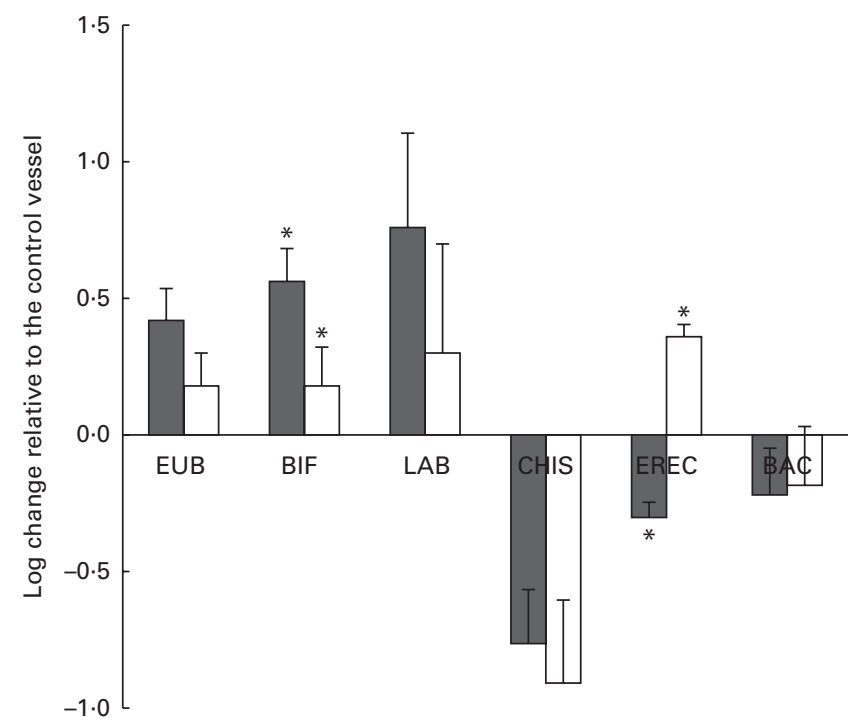

Fig. 4. Influence on colonic bacterial populations during the fermentation of FOS $(\square)$ and pure CGA ( $\square$ ). Bacterial changes expressed as $\log _{10}$ cells $/ \mathrm{ml}$ relative to the control vessel. Values are means, with their standard errors represented by vertical bars $(n 3)$. *Mean value was significantly different from that of the control vessel $(P<0.05)$. EUB, total bacteria; BIF, Bifidobacterium spp.; LAB, Lactobacillus/Enterococcus spp.; CHIS, Clostridium histolyticum group; EREC, C. coccoides-Eubacterium rectale group; BAC, Bacteroides spp. 
the validity of the work. Further in vivo work in this field is necessary to confirm these findings, although the present data provide an initial insight into the potential of CGA to act as a potential 'prebiotic' in the human large intestine.

\section{Acknowledgements}

The present study was supported by the Biotechnology and Biological Sciences Research Council's (BBSRC) Diet and Health Research Industry Club (DRINC) grant no. BB/ G530133/1. The BBSRC DRINC had no role in the design and analysis of the study or in the writing of this article.

The authors' contributions are as follows: C. E. M. was responsible for all the experimental work and drafting of the manuscript; G. R. G. was the co-principal investigator of the project and manuscript drafting; X. T. assisted with the experimental work; M.-J. O.-C., post-doctoral research assistant, assisted with the experimental work; D. S. M. was the co-principal investigator of the project and manuscript drafting; J. P. E. S. was the principal investigator of the project, experimental design and manuscript drafting.

There are no conflicts of interest to declare.

\section{References}

1. Mubarak A, Bondonno CP, Liu AH, et al. (2012) Acute effects of chlorogenic acid on nitric oxide Status, endothelial function, and blood pressure in healthy volunteers: a randomized trial. J Agr Food Chem 60, 9130-9136.

2. van Dijk AE, Olthof MR, Meeuse JC, et al. (2009) Acute effects of decaffeinated coffee and the major coffee components chlorogenic acid and trigonelline on glucose tolerance. Diabetes Care 32, 1023-1025.

3. Cropley V, Croft R, Silber B, et al. (2012) Does coffee enriched with chlorogenic acids improve mood and cognition after acute administration in healthy elderly? A pilot study. Psychopharmacology 219, 737-749.

4. Richelle M, Tavazzi I \& Offord E (2001) Comparison of the antioxidant activity of commonly consumed polyphenolic beverages (coffee, cocoa, and tea) prepared per cup serving. J Agr Food Chem 49, 3438-3442.

5. Moon JK, Yoo HS \& Shibamoto T (2009) Role of roasting conditions in the level of chlorogenic acid content in coffee beans: correlation with coffee acidity. J Agr Food Chem 57, 5365-5369.

6. Olthof MR, Hollman PC \& Katan MB (2001) Chlorogenic acid and caffeic acid are absorbed in humans. J Nutr 131, 66-71.

7. Stalmach A, Steiling H, Williamson G, et al. (2010) Bioavailability of chlorogenic acids following acute ingestion of coffee by humans with an ileostomy. Arch Biochem Biophys 501, 98-105.

8. Farah A, Monteiro M, Donangelo CM, et al. (2008) Chlorogenic acids from green coffee extract are highly bioavailable in humans. J Nutr 138, 2309-2315.

9. Monteiro M, Farah A, Perrone D, et al. (2007) Chlorogenic acid compounds from coffee are differentially absorbed and metabolized in humans. J Nutr 137, 2196-2201.

10. Rechner AR, Spencer JPE, Kuhnle G, et al. (2001) Novel biomarkers of the metabolism of caffeic acid derivatives in vivo. Free Radic Biol Med 30, 1213-1222.

11. Stalmach A, Mullen W, Barron D, et al. (2009) Metabolite profiling of hydroxycinnamate derivatives in plasma and urine after the ingestion of coffee by humans: identification of biomarkers of coffee consumption. Drug Metab Dispos 37, 1749-1758

12. Kassinen A, Krogius-Kurikka L, Makivuokko $\mathrm{H}$, et al. (2007) The fecal microbiota of irritable bowel syndrome patients differs significantly from that of healthy subjects. Gastroenterology 133, 24-33.

13. Hilton E, Kolakowski P, Singer C, et al. (1997) Efficacy of Lactobacillus GG as a diarrheal preventive in travelers. J Travel Med 4, 41-43.

14. Finegold SM, Molitoris D, Song Y, et al. (2002) Gastrointestinal microflora studies in late-onset autism. Clin Infect Dis 35, S6-S16.

15. Zhang H, DiBaise JK, Zuccolo A, et al. (2009) Human gut microbiota in obesity and after gastric bypass. Proc Natl Acad Sci U S A 106, 2365-2370.

16. Wallace TC, Guarner F, Madsen K, et al. (2011) Human gut microbiota and its relationship to health and disease. Nutr Rev 69, 392-403.

17. Gibson GR, Probert HM, Loo JV, et al. (2004) Dietary modulation of the human colonic microbiota: updating the concept of prebiotics. Nutr Res Rev 17, 259-275.

18. Van den Abbeele P, Verstraete W, El Aidy S, et al. (2013) Prebiotics, faecal transplants and microbial network units to stimulate biodiversity of the human gut microbiome. Microb Biotechnol 6, 335-340.

19. Gibson GR, Beatty ER, Wang X, et al. (1995) Selective stimulation of bifidobacteria in the human colon by oligofructose and inulin. Gastroenterology 108, 975-982.

20. Davis LM, Martinez I, Walter J, et al. (2010) A dose dependent impact of prebiotic galactooligosaccharides on the intestinal microbiota of healthy adults. Int J Food Microbiol 144, 285-292.

21. Ng SC, Hart AL, Kamm MA, et al. (2009) Mechanisms of action of probiotics: recent advances. Inflamm Bowel Dis 15, 300-310.

22. Neyrinck AM, Possemiers S, Verstraete W, et al. (2012) Dietary modulation of clostridial cluster XIVa gut bacteria (Roseburia spp.) by chitin-glucan fiber improves host metabolic alterations induced by high-fat diet in mice. J Nutr Biochem 23, 51-59.

23. Clavel T, Fallani M, Lepage P, et al. (2005) Isoflavones and functional foods alter the dominant intestinal microbiota in postmenopausal women. J Nutr 135, 2786-2792.

24. Tzounis X, Vulevic J, Kuhnle GGC, et al. (2008) Flavanol monomer-induced changes to the human faecal microflora. Br J Nutr 99, 782-792.

25. Tzounis X, Rodriguez-Mateos A, Vulevic J, et al. (2011) Prebiotic evaluation of cocoa-derived flavanols in healthy humans by using a randomized, controlled, double-blind, crossover intervention study. Am J Clin Nutr 93, 62-72.

26. Queipo-Ortuño MI, Boto-Ordóñez M, Murri M, et al. (2012) Influence of red wine polyphenols and ethanol on the gut microbiota ecology and biochemical biomarkers. Am J Clin Nutr 95, 1323-1334.

27. Parkar SG, Stevenson DE \& Skinner MA (2008) The potential influence of fruit polyphenols on colonic microflora and human gut health. Int J Food Microbiol 124, 295-298.

28. Mills CE, Oruna-Concha MJ, Mottram DS, et al. (2013) The effect of processing on chlorogenic acid content of commercially available coffee. Food Chem 141, 3335-3340.

29. Langendijk PS, Schut F, Jansen GJ, et al. (1995) Quantitative fluorescence in situ hybridization of Bifidobacterium spp. with genus-specific 16S rRNA-targeted probes and its application in fecal samples. Appl Environ Microb 61, 3069-3075. 
30. Manz W, Amann R, Ludwig W, et al. (1996) Application of a suite of 16S rRNA-specific oligonucleotide probes designed to investigate bacteria of the phylum Cytophaga-FlavobacterBacteroides in the natural environment. Microbiology 142, 1097-1106.

31. Hermie JM, Harmsen PE, Frits Schut \& Gjalt W Welling (1999) A $16 \mathrm{~S}$ rRNA-targeted probe for detection of lactobacilli and enterococci in faecal samples by fluorescent in situ hybridization. Microb Ecol Health and D 11, 3-12.

32. Franks AH, Harmsen HJM, Raangs GC, et al. (1998) Variations of bacterial populations in human feces measured by fluorescent in situ hybridization with group-specific $16 \mathrm{~S}$ rRNA-targeted oligonucleotide probes. Appl Environ Microb 64, 3336-3345.

33. Daims H, Brübl A, Amann R, et al. (1999) The domainspecific probe EUB338 is insufficient for the detection of all bacteria: development and evaluation of a more comprehensive probe set. Syst Applied Microbiol 22, 434-444.

34. Kolida S \& Gibson GR (2007) Prebiotic capacity of inulintype fructans. J Nutr 137, 2503S-2506S.

35. Sako T, Matsumoto K \& Tanaka R (1999) Recent progress on research and applications of non-digestible galactooligosaccharides. Int Dairy J 9, 69-80.

36. Woodmansey EJ, McMurdo MET, Macfarlane GT, et al. (2004) Comparison of compositions and metabolic activities of fecal microbiotas in young adults and in antibiotic-treated and non-antibiotic-treated elderly subjects. Appl Environ Microb 70, 6113-6122.

37. Collado MC, Gueimonde M, Hernandez M, et al. (2005) Adhesion of selected Bifidobacterium strains to human intestinal mucus and the role of adhesion in enteropathogen exclusion. J Food Prot 68, 2672-2678.

38. Singh J, Rivenson A, Tomita M, et al. (1997) Bifidobacterium longum, a lactic acid-producing intestinal bacterium inhibits colon cancer and modulates the intermediate biomarkers of colon carcinogenesis. Carcinogenesis 18, 833-841.
39. Gill HS, Rutherfurd KJ, Cross ML, et al. (2001) Enhancement of immunity in the elderly by dietary supplementation with the probiotic Bifidobacterium lactis HN019. Am J Clin Nutr 74, 833-839.

40. Vulevic J, Drakoularakou A, Yaqoob P, et al. (2008) Modulation of the fecal microflora profile and immune function by a novel trans-galactooligosaccharide mixture (B-GOS) in healthy elderly volunteers. Am J Clin Nutr 88, $1438-1446$.

41. Hidalgo M, Oruna-Concha MJ, Kolida S, et al. (2012) Metabolism of anthocyanins by human gut microflora and their influence on gut bacterial growth. J Agr Food Chem 60, 3882-3890

42. Jaquet M, Rochat I, Moulin J, et al. (2009) Impact of coffee consumption on the gut microbiota: a human volunteer study. Int J Food Microbiol 130, 117-121.

43. Couteau D, McCartney AL, Gibson GR, et al. (2001) Isolation and characterization of human colonic bacteria able to hydrolyse chlorogenic acid. I App Microbiol 90, 873-881.

44. Salminen S, Bouley C, Boutron M-C, et al. (1998) Functional food science and gastrointestinal physiology and function. Br J Nutr 80, S147-S171.

45. Canani RB, Costanzo MD, Leone L, et al. (2011) Potential beneficial effects of butyrate in intestinal and extraintestinal diseases. World J Gastroenterol 17, 1519-1528.

46. Duerre P (2005) Handbook on Clostridia. Boca Raton: CRC Press.

47. Vermeiren J, Van den Abbeele P, Laukens D, et al. (2012) Decreased colonization of fecal Clostridium coccoides/ Eubacterium rectale species from ulcerative colitis patients in an in vitro dynamic gut model with mucin environment. FEMS Microbiol Ecol 79, 685-696.

48. Hughes SA, Shewry PR, Li L, et al. (2007) In vitro fermentation by human fecal microflora of wheat arabinoxylans. J Agric Food Chem 55, 4589-4595. 